\title{
Identifying and Prioritizing Barriers to Health Tourism Using the Analytical Hierarchy Process
}

\author{
Mohammadkarim Bahadori', Raziyeh Malmir ${ }^{2}$, Khalil Alimohammadzadeh², Maryam Yaghoubi', Seyed \\ Mojtaba Hosseini ${ }^{2}$
}

${ }^{1}$ Health Management Research Center, Baqiyatallah University of Medical Sciences, Tehran, Iran

${ }^{2}$ Department of Health Services Management, Tehran North Branch, Islamic Azad University, Tehran, Iran

Corresponding Author: Raziyeh Malmir, Ph.D. Student in Health Services Management, Department of Health Services Management, Tehran North Branch, Islamic Azad University, Tehran, Iran. Email: malmir.arash@yahoo.com

Received November 6, 2016; Accepted January 18, 2017; Online Published February 19, 2017

\begin{abstract}
Introduction: Iran offers many advantages for health tourism, e.g., low costs, high quality healthcare, qualified doctors, and abundant natural attractions, but there are also obstacles to the development of health tourism in Iran. This study aimed to identify and prioritize the barriers to health tourism in hospitals affiliated with Tehran University of Medical Sciences.

Methods: This cross-sectional study was conducted in the first 6 months of 2016. Six main components were identified based on experts' opinions; then, based on these components, a questionnaire for pairwise comparison was produced and completed by the same experts. The analytical hierarchy process (AHP) model was used to prioritize the identified factors.

Results: Results showed that among the barriers to health tourism in the investigated hospitals, the most important obstacle is the unfamiliarity of medical staff with foreign languages with a weight of 0.268 . Lack of manpower and inappropriate physical were ranked second and third in priority with weights of 0.214 and 0.157 , respectively.

Conclusion: Considering the available capacities and potentials, effective and impressive steps can be taken to economically develop the medical tourism industry in Iran.

Keywords: Health tourism, AHP technique, Iran
\end{abstract}

Citation: Bahadori M, Malmir R, Alimohammadzadeh K, Yaghoubi M. Identifying and prioritizing barriers to health tourism using the analytical hierarchy process. Int J Travel Med Glob Health. 2017;5(1):33-35. doi:10.15171/ijtmgh.2017.06.

\section{Introduction}

Medical tourism as a branch of health tourism represents a growing industry that creates opportunities for patients to obtain medical services by traveling beyond their national borders. ${ }^{1}$ Due to the rises in costs and competition in the healthcare sector, ${ }^{2}$ the tourism industry has become one of the largest industries in the world, and an intense rivalry exists among many countries to attract tourists. ${ }^{3}$ According to the World Bank, the third largest investment arena in the world is related to health tourism. ${ }^{4}$ Globally in 2007, revenues from health tourism exceeded $\$ 60$ billion, ${ }^{5}$ and this number rose to $\$ 100$ billion in $2009 .{ }^{6}$ Developing countries are good health tourism destinations because of lower costs for medical services. ${ }^{7}$ Long queues for treatment, especially in Canada, Britain, and Australia, ${ }^{8,9}$ and a lack of health insurance for some services like cosmetic surgery create a willingness in people to travel to developing countries for medical services. ${ }^{10}$

Countries such as India, Thailand, and Singapore have a bright future in the field of health tourism. The lower cost of treatment in these countries can make them among the first countries in tourism. ${ }^{11}$ Among developing countries, Iran is one of the active centers for health tourism in the Middle East. ${ }^{12}$ Because of Iran's advantages for health tourists such as low costs, the high quality of healthcare, qualified doctors, and abundant natural attractions, the country can take advantage of health tourism. ${ }^{13}$ However, there are obstacles to the development of health tourism in Iran. Previous studies have determined the factors that constitute the most important barriers to health tourism, and they include laws and regulations, government support, the local community's costs and health requirements, ${ }^{14}$ a lack of space and proper medical facilities, ${ }^{15}$ a shortage of skilled human resources in some medical disciplines, a lack of ISO and JCI credentials to attract foreign patients, reluctance to market healthcare at the university level, ${ }^{16}$ a lack of medical specialists and markets, the lack of an information technology infrastructure, and a lack of advertising in medical tourism. ${ }^{16}$

University hospitals are the biggest units affiliated with the

Copyright (C) 2017 The International Journal of Travel Medicine and Global Health. This is an open-access article distributed under the terms of the Creative Commons Attribution License (http://creativecommons.org/licenses/by/4.0), which permits unrestricted use, distribution, and reproduction in any medium, provided the original work is properly cited. 
Ministry of Health and Medical Education and are responsible for providing health services to people. These universities offer new opportunities to patients from other countries by applying the abilities of sophisticated professors and advanced, specialized equipment. The current study aimed to identify barriers to health tourism in hospitals affiliated with Tehran University of Medical Sciences, the largest medical university in Iran.

\section{Methods}

This cross-sectional study was conducted in the first 6 months of 2016 and purposed to prioritize the effective components of obstacles to health tourism in hospitals affiliated with Tehran University of Medical Sciences from the perspective of its faculty members and experts using the analytical hierarchy process (AHP) model.

The study sample consisted of 25 faculty members and 40 administrators and managers of 12 hospitals affiliated with Tehran University of Medical Sciences who were purposefully selected through the non-probability sampling method. The inclusion criterion was having at least 5 years of work experience in a hospital.

The questionnaire used in this study consisted of 2 sections. The first section collected demographic information, and the second section investigated the effective components of obstacles to health tourism which were constructed based on pairwise comparisons. Based on a review of literature in this field, more than 20 relevant factors were extracted. Then, based on the opinions of faculty members and experts, the following 6 factors were generated for use in this study: unfamiliarity of the hospital's medical staff with foreign languages, a shortage in human resources, a lack of adequate physical space, rigid regulations, the lack of a suitable advertising website for the hospital's International Patients Department (IPD), and the lack of communication with other organizations (hotels, airports, etc.). To confirm its validity, the questionnaire was distributed among 10 professors and experts. The reliability of the questionnaire was tested using Cronbach $\alpha(0.8)$. The results indicated that the questionnaire had validity and a high level of reliability. In the analytical hierarchy, after determining the purpose of this study, the components were specified in the first step. The questionnaire was structured on a numerical scale of scores from 1 to 9 , with 1 representing the equal importance of 2 components relative to each other and 9 representing the heavy importance of 2 components relative to each other. Finally, by calculating the geometric mean of any subcriteria to another factor, priorities were determined. Data was analyzed using Expert Choice software.

\section{Results}

Six main components of barriers to health tourism in hospitals affiliated with Tehran University of Medical Sciences were identified. At first, in order to prioritize the variables, a matrix of paired comparisons was formed. Afterwards, the variables were prioritized by using the geometric mean. The results are presented in Table 1 and Figure 1.

In this study, the compliance rate was 0.7 , which represents the reliability of the findings. Results showed that among the barriers to health tourism in the investigated hospitals and based on the opinions of faculty members and experts, the most important obstacle was unfamiliarity of medical staff with foreign languages with a weight of 0.268 . Lack of manpower and inappropriate physical space were ranked second and third on the priority list with weights of 0.214 and 0.157 , respectively.

\section{Discussion}

Health tourism is a growing and important issue in Iran, although the infrastructure needed to develop this type of tourism is insufficient. ${ }^{16}$

There are many challenges and obstacles in this field. ${ }^{15}$ The present study used the analytical hierarchy method, which gave highly accurate results, to identify barriers to health tourism in hospitals affiliated with Tehran University of Medical Sciences. Among the barriers identified, the most important ones were the unfamiliarity of medical staff with foreign languages (0.268), a lack of manpower (0.214), and inappropriate physical space $(0.157)$. The lack of foreign language skills in nurses and hospital staff, especially English and Arabic, had a high value for patient absorption.

Health tourism is one of the main reasons Arab Muslims travel to Iran. More than $70 \%$ of patients who come to Iran originate from countries such as Saudi Arabia, Iraq,

Table 1. Prioritization of Components of Barriers to Health Tourism in Hospitals Affiliated With Tehran University of Medical Science

\begin{tabular}{lll}
\hline Component & Weight & Priority \\
\hline $\begin{array}{lll}\text { Unfamiliarity of medical staff with foreign } \\
\text { languages }\end{array}$ & 0.268 & 1 \\
$\begin{array}{l}\text { Lack of manpower } \\
\begin{array}{l}\text { Inappropriate physical space } \\
\text { Inadequate laws and regulations }\end{array}\end{array}$ & 0.214 & 2 \\
$\begin{array}{l}\text { Lack of advertising website on the internet for } \\
\text { hospital's IPD }\end{array}$ & 0.154 & 4 \\
$\begin{array}{l}\text { Communication of hospital with other } \\
\text { organizations }\end{array}$ & 5 & 5 \\
\hline
\end{tabular}

Priorities with respect to:
Goal: The Obstacles of Health tourism
Unfamiliarity of medical staff with foreign languages
Lack of manpower
Inappropriate physical space
Lack of Advertising
Inappropriate communication of hospital with other organizations $\mathbf{. 1 2 6}$
Inadequate laws and regulations
Inconsistency = 0.07
with 0 missing judgments.

Figure 1. Prioritization of Barriers to Health Tourism. 
Azerbaijan, Pakistan, and Oman. Having English and Arabic translators could be useful in resolving this barrier, ${ }^{10,17}$ and this issue has been emphasized. A lack of manpower was identified as the second obstacle in the studied hospitals. Offering appropriate healthcare services requires sophisticated and sufficient manpower, and this must be solved quickly; a shortage of manpower can lead to a decline in the quality of health services. Manpower shortages and a lack of specialized capabilities among medical staff are known weak points in the expansion of Iran's health tourism. ${ }^{15}$

One other issue in medical tourism is designing the hospital space. The construction of hospital hotels and the creation of an appropriate atmosphere for people who accompany the patients are wise actions in developing health tourism and suggest a comprehensive viewpoint of health tourism. The lack of an appropriate website for advertising on the Internet is another obstacle identified in this study. In addition to information regarding doctors, medical expenses, and the durations of treatments that hospitals should have registered in their systems, it is necessary to provide potential patients with a comprehensive database containing authentic agency and hospital information which can help the health tourist.

\section{Conclusion}

Considering the available capacities and potentials in Iran, effective and impressive steps can be taken to economically develop the tourism industry, such as increasing investments and collaboration between universities and other relevant organizations.

\section{Authors' Contributions}

All authors significantly contributed towards this study.

\section{Conflict of Interest Disclosures}

The authors have no conflicts of interest.

\section{Ethical Approval}

Not applicable.

\section{Funding/Support}

The authors received no specific funding for this work.

\section{Acknowledgments}

The authors thank all persons who participated in this study.

\section{References}

1. Breitrück V, Nunn E. Health \& Medical Tourism. In: Papathanassis
A, ed. The Long Tail of Tourism. Springer; 2011:57-67.

2. Yaghoubi M, Agharahimi Z, Karimi S, Javadi M. Factors affecting patients' preferences in choosing a hospital based on the mix marketing components in Isfahan (Persian). Hakim Res J. 2011;14(2):106-114.

3. Moghavvemi S, Ormond M, Musa G, et al. Connecting with prospective medical tourists online: a cross-sectional analysis of private hospital websites promoting medical tourism in India, Malaysia and Thailand. Tour Manag. 2017;58:154-163. doi:10.1016/j.tourman.2016.10.010.

4. Goodarzi M, Haghtalab N, Shamshiry E. Wellness tourism in Sareyn, Iran: resources, planning and development. Current Issues in Tourism. 2015:19(11):1071-1076. doi:10.1080/13683500.201 5.1012192 .

5. Chen LY, Wang T-C. Optimizing partners' choice in IS/IT outsourcing projects: the strategic decision of fuzzy VIKOR. International Journal of Production Economics. 2009;120(1):233242. doi:10.1016/j.ijpe.2008.07.022.

6. Mohamad WN, Omar A, Haron MS. The moderating effect of medical travel facilitators in medical tourism. Procedia Soc Behav Sci. 2012;65(3):358-363. doi:10.1016/j.sbspro.2012.11.134.

7. Morovati Sharifabadi A, Asadian Ardakani F. A model for health tourism development using fuzzy TOPSIS and interpretive structural modeling in Yazd province (Persian). J Health Adm. 2014;17(55):73-88.

8. Garcia C, Pagan JA, Hardeman R. Context matters: where would you be the least worse off in the US if you were uninsured? Health Policy. 2010;94(1):76-83. doi:10.1016/j.healthpol.2009.08.010.

9. Turner L. 'First world health care at third world prices': globalization, bioethicsandmedicaltourism. BioSocieties.2007;2(3):303-325.

10. Awadzi W, Panda D. Medical tourism: globalization and marketing of medical services. The Consortium Journal of Hospitality and Tourism. 2005;11(11):75-80.

11. Ansari I, Saman K. Impact of globalization on medical tourism in developing countries like India. Int J Eng Technol Manag Appl Sci. 2014;12(7):62-68.

12. Hosseini SM, Maher A, Safarian O, et al. Development Strategy of Health Tourism in Iran. Int J Travel Med Glob Health. 2015;3(4):153-158. doi:10.20286/ijtmgh-0304143.

13. Izadi M, Ayoobian A, Nasiri T, Joneidi N, Fazel M, Hosseinpourfard MJ. Situation of health tourism in Iran opportunity or threat (Persian). Journal of Military Medicine. 2012;14(2):69-75.

14. Heung VCS, Kucukusta D, Song H. Medical tourism development in Hong Kong: an assessment of the barriers. Tour Manag. 2011;32(5):995-1005. doi:10.1016/j.tourman.2010.08.012.

15. Ghanbari S, Hajinejad A, Rahmani P. Formulating strategic plan of medical tourism development. Int J Travel Med Glob Health. 2014;2(4):194-154.

16. Amouzagar S, Mojaradi Z, Izanloo A, Beikzadeh S, Milani M. Qualitative examination of health tourism and its challenges. Int J Travel Med Glob Health. 2016;4(3):88-91. doi:10.21859/ ijtmgh-040304.

17. Nasiripour AA, Tabibi J, Raeisi A, Jahani MA. Designing a model for hospital services globalization in Iran (Persian). Journal of Babol University of Medical Sciences. 2010;12(1):86-94. 